\title{
浅谈机电一体化技术应用及其发展
}

郡杰

乌鲁木齐昆仑新水源科技股份有限公司

DOI:10.32629/hwr.v4i5.2989

[摘 要] 机电一体化是社会经济快速发展的需要,同时也是科学技术发展的体现,其主要是把相关的机械、电子以及信息技术实施融合的一项 综合与实践技术,其合理运用对于促进社会经济发展具有重要影响,基于此,本文阐述了机电一体化技术及其应用特征,对机电一体化技术的应用 及其发展进行了探讨分析。

[关键词] 机电一体化技术; 特征; 应用; 发展

机电一体化技术是以机械电子理论为基础, 通过运用先进技术, 对相 关内容开展全方位、系统化分析, 从而提升工作效率。同时将机电一体化 技术与工程机械行业的相结合, 可以有效提升机械运行与工作效率。

\section{1 机电一体化技术的分析}

1. 1 机械本体技术。机械本体技术的合理运用, 需要就提升精度、增强 性能以及减少质量等方面进行分析。并且只有通过减轻机械本体质量, 才 能发展小型的驱动系统, 钢材是当前机械产品的主要材料, 对其结构进 行改善, 可以有效减轻质量, 同时也能运用非金属复合材料减轻机械产 品质量。

1. 2 传感技术。传感技术的合理运用, 需要保障传感器的可靠、灵敏度 及其精确等方面。在其应用过程中, 为了防止电干扰, 一般运用光纤电缆传 感器。对外部信息传感器而言, 需要发展非接触型检测技术。

1. 3 信息处理技术。机电一体化与微电子学进步以及信息处理设备应 用等方面密切相关。因此为了发挥机电一体化的功能作用, 需要保证信息 处理设备的安全可靠, 从而提升其处理速度。

1. 4 驱动技术。电机作为驱动机构已被广泛采用, 但在快速响应和效率 等方面还存在一些问题。目前正在积极发展内部装有编码器的电机以及控 制专用组件-传感器-电机三位一体的伺服驱动单元。

1. 5 接口技术。为了与计算机进行通信, 必须使数据传递的格式标准 化、规格化。接口采用同一标准规格不仅有利于信息传递和维修,而且可 以简化设计。

1.6 软件技术。软件与硬件必须协调一致发展。为了减少软件的研制 成本, 提高生产维修的效率, 要逐步推行软件标准化, 包括程序标准化、程 序模块化、软件程序的固化、推行软件工程等。

\section{2 机电一体化技术应用的主要特征}

2. 1 高精度特征。机电一体化技术的合理应用能够提升行业的发展 水平, 保障现代机械产品的高精度。同时, 这种机械自动化的方式来可以 缩减一定的人工成本, 减少企业的人力成本支出, 切实有效提高企业的 成本效益。

2. 2 自行检测特征。机电一体化技术在机械设备运行过程中的应用， 可以对机械设备系统中的不同项目开展有效检测, 假如机械设备系统存在 问题, 其可以及时反映给从业人员, 同时可以修复所反映的问题, 从而保证 机械设备的可靠运行。

\section{3 机电一体化技术的应用及其发展}

3. 1 机电一体化技术的应用分析。(1) 计算机集成技术应用。其主要是 通过对各系统进行整合, 达到将全局动态进行综合展示的目的, 因此可以 说计算机的集成在一定程度上满足了对产品研制、生产和经营等各个流程
进行有机结合的要求, 为产品开发提供了有效信息。(2) 数控机床中的应 用。机电一体化在数控机床操控中的合理运用, 能够有效提升其精确度, 而且数控机床模块化结构也是依托于该技术而产生。而且机电一体化在数 控机床操控中的合理运用, 不仅保障了数控机床功能, 还在很大程度上为 产品生产速度的提高提供了理论依据。(3) 柔性的制造系统。经过机电一 体化相关技术的指导而不断完善的制造系统, 具有的最大特征在于能够根 据企业和市场的实际需求对产品生产的种类和数目进行及时更改。(4) 在 机器人中的应用。机电一体化技术运用在机器人研制过程中共分为: 第一 阶段, 机器人可以按照要求对特定的动作进行不断重复, 这一阶段的机器 人无法针对不同的环境和对象将自身的功能进行选择性展示; 第二阶段, 机器人可以对其所处环境的信息进行获取和分析, 并且选择相应的动作进 行反馈, 这一阶段的机器人已经开始向实用性进行转化; 第三阶段, 机器人 具有了人工智能, 因此它们不仅可以进行复杂的思考, 还可以将自身的感 知进行表达和传递。

3.2机电一体化技术发展的分析。(1)网络化。网络的一体化让信息的 获取和传播途径更加快捷, 现场总线技术和局域网技术让一些家用电器智 能网络化成为了可能。(2) 高性能化。机电一体化技术的高性能特征就是 指运用机电一体化技术的相关设备在稳定性、精准性和速度等方面都能快 速发展。且模块化也是未来机械生产的主要方向, 为提高机械设备的检修 效率, 就可利用模块化生产技术, 一旦设备出现故障, 只需要更换模块就可 完成维修。(3) 智能化。目前现实生活可以感受到很多的机电产品都在朝 着智能化方向发展, 很多机电产品在生产的过程中已经开始模仿人类的知 觉能力。(4) 绿色化。随着我国工业化建设脚步的不断加快, 工业技术发展 和我国生态环境建设出现了一定的矛盾, 为了调节二者之间的关系, 机电 一体化技术就需要朝着绿色、低碳的方向进行发展。

\section{4 结束语}

综上所述, 机电一体化技术是应用机械自动技术、电子计算机技术、 信息变换以及传感测控与软件编程技术等的系统化技术。目前其在诸多领 域得到广泛应用, 所以为了充分发挥其作用, 必须加强对机电一体化技术 的应用与发展进行分析。

\section{[参考文献]}

[1]彭飞.机电一体化技术在工程机械中的应用 [J].集成电路应 用,2020,37(03): 70-71.

[2]王金玉,牛肖梅.工程机械机电一体化技术的应用与发展[J].科技创 业家,2013,(18):83.

[3] 雷泱.工程机械中机电一体化技术的应用探究 [J]. 南方农 机,2020,51(04):179. 